\title{
Museari: Art in a Virtual LGBT Museum Promoting Respect and Inclusion
}

https://doi.org/10.51897/interalia/NQBD3367

\author{
Ricard Huerta \\ Universitat de Valencia \\ ORCID: 0000-0002-1430-3198
}

\begin{abstract}
Museari is an online museum dedicated to upholding human rights and sexual diversity through art, history, and education. Museari was born in 2015 and since then more than 70 exhibitions have been presented. This paper analyzes Museari's interest in teacher training, something that has been especially positive during the Covid-19 pandemic. The objective of the research is to reflect on the opportunity to use a virtual museum to address issues of art and education. For data collection, we used assessment instruments specific to the case study, such as diagnoses, discussions, focus groups, and participant observation. We highlight museum's positive reception by the students, particularly the role it plays in overcoming stereotypes and conventional taboos to achieve inclusive environments.
\end{abstract}

Keywords: queer studies, queer art, education, museum, teacher training.

\section{Introduction}

Examining the initial training of primary school teachers, we found a lack of art education in the curricula and classrooms. This deficit is due to the fact that little attention is paid to art in the school programs (Huerta and Domínguez, 2020). Since the Spanish educational system makes no effort to counteract ignorance of the visual arts at all levels, from kindergarten to the university, there is little curricular interest in training students in art. Discussions of sexual diversity are likewise practically absent from the teacher-training classroom. Students arrive at the university with serious gaps in their knowledge: they know little about both art and LGBT cultures. In effect, they are completely out of touch with the dissident realities, and with the artistic cultural heritage in general (Panciroli, 2016).

We think that it is possible to overcome this problem by creating an environment conducive to learning about the arts and dissident realities. We believe that such an environment is necessary for improving general knowledge about art, artists, and sexual diversity, and teacher training is a significant way of achieving this. Exposing future teachers to art also creates room discussing art made by LGBT artists. In addition to a theoretical training, we incorporate art workshops and participatory experiences through which future teachers can put their creative potential into practice, taking advantage of the digital media (Rodríguez Ortega, 2018). 
Through art education we promote situated knowledge, as well as fostering creativity and multiculturalism. We approach this challenge by combining theory with workshops; we attempt to translate learning into lived experience; we promote creative thinking and develop proposals that defend "things well done" (Sennett, 2009). These initiatives have yielded very positive results. Our research indicates that there is a need to incorporate LGBT art and creativity in teacher training to make future teachers more respectful of diversity in an inclusive and demanding educational environment.

Studying the art made by artists from the Museari online museum (https://www.museari.com) allows us to reflect on and question traditional gender roles and gender prejudices. We promote respect for diversity, fostering subjecttivities free of stereotypes, attending to issues as diverse as the gender transition that trans people undergo and homophobic bullying of the most vulnerable students.

Art and culture are part of the collective imagination and they connect the present with the past (Mérida Jiménez, 2020). They may also be understood as the images that transmit discourses created and disseminated by the power to generate certain impressions, expanding the imagination in which political ideals persist and influence public opinion. According to Duncum (2008), visual culture exerts a particularly powerful influence on the people who consume it without questioning the information that it conveys as absolute truth (Pérez Navarro, 2018). Although this applies to all age groups, visual has a stronger influence on the young, who are in the process of discovering their environment, and more specifically, on those people who make up the school body, both students and teachers (Alonso-Sanz, Jardón and Lifante, 2019). The power of the audiovisual media and communication companies is also very important.

From the wide range of available visual culture, for our project we selected the culture of sexual dissidence and art created from a queer perspective. We focus on artists and works exhibited in the Museari online museum, which specializes in LGBT advocacy (Arriaga and Aguirre, 2013). We emphasize inclusivity in the classroom, attending to the need to incorporate quality visual literacy, understood as that which teaches students to decode, analyze, question, and criticize the messages they receive (Huerta, 2010). We assume that various visual images, including art, can be used as devices for reflecting on inequalities. Through these strategies, students are encouraged to develop respect for diversity while being fully involved in each activity.

\section{Methodology}

The present research is qualitative, based on a hybrid methodology that includes a case study (Stake, 2005). We also incorporate Arts-Based Educational Research (Rolling, 2017). We are interested in improving teacher training in the field of art, artistic culture, visual culture, art education, and sexual diversity, questioning our teaching practices and the ways in which we generate knowledge, interact, and learn. We incorporate experiences and knowledge from alterity. We affirm the everyday and the diverse, which have always been marginalized. We promote reflection, creativity and the construction of knowledge in learning environments, favoring a dialogue with social problems from critical peda- 
gogy, humanized praxis, and implied participation. This formative openness fosters the development of an environment conducive to reflection. Those who inhabit the learning spaces are able to debate about the types of difference that merit inclusion in the shared experiences (Hernández and SanchoGil, 2015). All this allows us to problematize the teaching practices that affect us, through a pedagogy that crosses limits.

This article analyzes a research project carried out in university classrooms, where we covered aspects of diversity and inclusion and trained the participants in visual literacy (Duncum, 2015), involving them in the teaching processes. We also problematized the educational space and its power relations as a reflection of our society, where conditions of inequality are reproduced and dissidents are discriminated against. Our reflection made it possible to give visibility to sexual and gender diversity, so the context determined how to approach the learning process.

We conducted an analysis of visual sources and a comparison of different artists through case studies, to carefully observe from the perspective of the teacher-in-training what the students pursuing the degree of primary-school specialist teacher detect with respect to the subject studied. Based on a survey and the comments provided by the focus group, we reached a series of results. According to the categories elaborated by Robert Stake (2005), this is an instrumental case study, since it involves generalizing from a specific situation, examining the case to delve into a topic, so that the case supports the formulation of statements about the object of study. The power of art serves both to show as well as to hide certain realities, ultimately affecting our analysis of social and communicative processes (Briggs and Burke, 2009). Unraveling media products through visual culture will be beneficial for our students as future teachers (Karpati, Freedman, Castro, Kallio-Tavin and Heijnen, 2017).

We need a school highly impregnated with the knowledge and values of art, art history, and artistic practice, incorporating LGBT diversity; a school in which teachers' own visual culture serves as an incentive to work towards greater diversity (Escudero, 2017). The school environment is pervaded by the visual, so studying its schemes of visual culture allows us to investigate sociological, semiotic, and artistic issues, promoting teaching practices aimed at educational innovation (Planella and Pie, 2012). We reinforce these actions to help our university students to grow, precisely at the time of initial training. We take into account the interests of the students themselves, attending to the construction of their personal narratives, activating artistic practices in pedagogical mediation environments, conceiving education from a critical perspective (Escaño, 2019).

Our projects incorporate artistic experiences as gears of social transformation. We are interested in discovering our environment in order to improve it. Since the struggle against discrimination plays a fundamental role in this work, we propose a school environment as a place for reflective processes, generating debates about problems that directly affect the student body, such as gender discrimination, marginalization, or inequality. 
We build artistic knowledge based on the direct experience of art (Hamlin and Fusaro, 2018), fostering social involvement and a political sense that goes from the intimate and personal to the shared and common (Péchin, 2017). We generate critical thinking from artistic practice to increase both creativity and freedom in a transforming society, so that art education becomes a motor for social transformation (Huerta, 2016). We develop a research model that understands artistic practices as articulating agents of subjectivities, always attentive to gender problems and social issues. Ours is a qualitative approach and its character is exploratory due to the novelty of the issues addressed in this particular context (Yin, 2009).

\section{Case Study: “Museari Artists" Project}

A total of 100 Spanish students of the Arts and Humanities participated in the project which was carried out as part of an optional course titled "Didactic Proposals in Art Education" chosen by students interested in the arts and their educational possibilities. Surveys were delivered to 100 students enrolled in the Primary School Teacher's Degree program at the Faculty of Education of the University of Valencia, with $100 \%$ responding. $72 \%$ of the respondents were female and $28 \%$ male. The students' average age was 22 . The majority (88\%) were between the ages of 20 and 30.

The aim of the study was to investigate the possibilities of using images from artivism (activism thar deploys art) to transform everyday environments by eliminating prejudices and taboos regarding non-normative sexuality and gender roles. We introduced the participants to artistic languages that go beyond mere representation and that promote expressive and reflective processes. The study stimulated students to rethink the social dynamics in the school environment and the need to distance themselves from gender violence, homophobia, and transphobia. As future teachers, they were encouraged to affirm gender and sexual diversity, create a more collaborative classroom environment, and use activities associated with art to improve situations of inequality.

Since the study was carried out during the academic year 2020-2021, we had to make the double effort of investigating while simultaneously attending to the changes brought about by the Covid19 pandemic, which sometimes forced us to change from the face-to-face to the virtual format. In the classroom we initiated debates based on the students' initial reflections on art and we found that the pandemic affected the opinions and responses to the problems presented. The dynamics of each activity also included creative and participatory workshops, with which we attempted to help students overcome their prejudices regarding art and its dynamics, especially those related to the art market. The data collection and construction techniques were defined based on different parameters, namely: initial diagnosis of each activity; development of workshops; organization of focus groups; and final diagnosis of each action performed. The analytical procedure was established on the basis of the discussion of the data collected through qualitative research. Categories of analysis emerging from the initial diagnosis were established, and a survey of the data was carried out based on the construction of a double entry matrix. From the beginning, what the students already knew was taken 
into account, since their previous knowledge can open paths and integrating options, in addition to allowing them fully participate in the study.

The analysis of the collected data allowed us to elaborate an inquiry about what university students who are training as teachers know about the influence of the arts on their knowledge of certain problems (Giroux, 2018). Since in everyday life sexual diversity tends to be invisible, art can be attractive for future teachers as a way of rediscovering concepts such as "dissidence" or "diversity" that allow us to get closer to the lived reality of people with the greatest need for care. Teachers should be trained in art and artistic cultures, including the social, cultural, and economic aspects of art (Freire, 2015). Other issues highlighted by our analysis arise from the study and knowledge of meaning structures based on humor, irony, or the conceptual reworking that the language of art allows (Barthes, 1986).

We began with the assumption that we must be attentive to the realities that affect people who suffer harassment or persecution for their sexual dissidence, especially students and teachers. In order for citizens to be aware of minorities and attend to their needs, their problems must be made visible. We can approach dominant narratives from a skeptical perspective, thus achieving a greater degree of immunity against the messages that such narratives continue to spread (Appiah, 2018). The communicative role of art has a relevant social function (Benjamin, 1969).

At the beginning of the project, we presented the online museum and the way to access its more than 70 temporary exhibitions. These are samples in which topics related to the different experiences of LGBT groups are addressed. Talking with our students about these artists through works in the virtual museum, we encouraged them to generate educational resources for the future, since as teachers they would need arguments to connect art, diversity, and education (Greteman, 2017) and they would be sharing with their students their interpretations of everyday life (Dewey, 2008). We also incorporated historical references to movements in defense of LGBT rights which paved the way for a true effervescence of activism.

The workshop involved developing a didactic proposal based on the knowledge of the work of artists exhibited in Museari. In the course of an initial preparatory and participatory class, a series of sessions were taught in which the topics covered in Museari exhibitions were explained. Then each student made their personal proposal, based on a sample of art that was especially meaningful to them. A number of the students stated that they "do not know much about art" and that "they were never good at art." When it comes to incorporating art into teaching, starting with what they already know greatly simplifies the task. For this reason we resorted to the students' formative experiences involving art. Significantly, we were not working with students of art or art history, but rather future elementary school teachers, undergraduate students who only take just one required arts course (6 credits, one semester) during their academic career. 


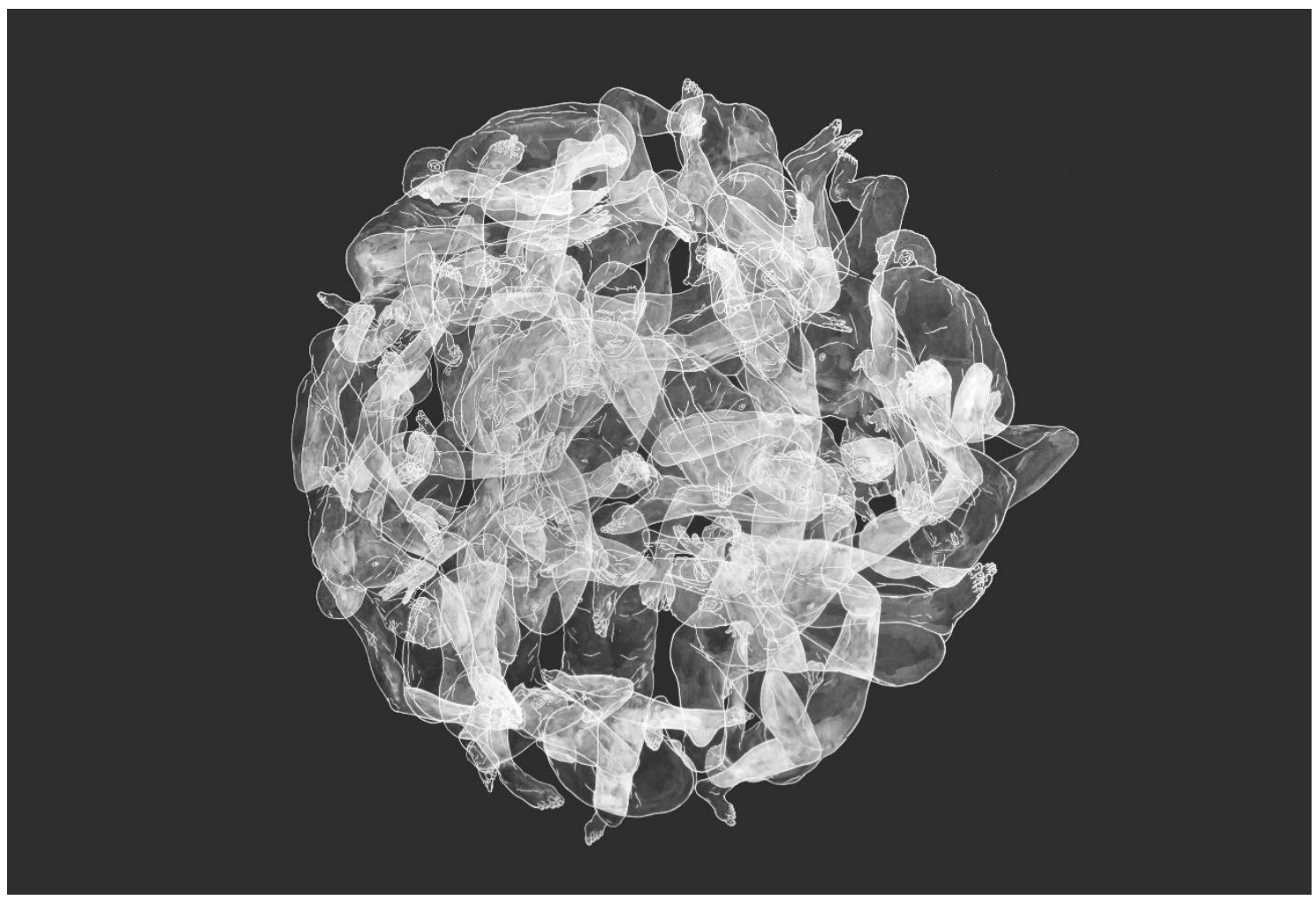

Figure 1. Snowball 32, Moisés Mahiques. Work exhibited in Museari.

8\% of the participants chose the exhibition Game Over \#2 by the artist Moisés Mahiques (fig. 1). The phrase "game over" has always been associated with the world of video games, and it has always indicated the end of the game which the player either wins or loses. In this case, "game over" serves as a metaphor that highlights certain elements of control and order hidden under something as innocent as the act of playing. Using the concept of the game, associated with fun and childhood, allows us to conduct an exercise in which the participants reflect on the question when and how we begin to build or define certain roles. These roles are often the result of different forms of power, discipline, and submission within in a particular social model.

$15 \%$ of students chose the exhibition The Line of your Back by Abel Azcona (fig. 2), a retrospective consisting of seven pieces on the theme of sexuality and eroticism. Azcona is an artist associated with processual art. He hybridizes performance with photography, video art, installation, and sculpture. Among the controversial themes he explores are: human rights, social injustices, gender, prostitution, neglect, violence, child abuse, feminism, sexuality, pornography, inequalities, politics, terrorism, and religion. Over 500 performance projects and more than 100 individual exhibitions at the international level make Abel Azcona a key figure in social and political art. His work, which has been seen in more than forty countries on four continents, can be interpreted under two axes, the autobiographical and the critical, which are in a constant synergy. Azcona works from the personal and the intimate to the social and pedagogical, with the aim of evoking a collective catharsis. As a 
form of social and political critique, Azcona's art implies a denunciation of a society guilty of its own experience marked by pain and abandonment.

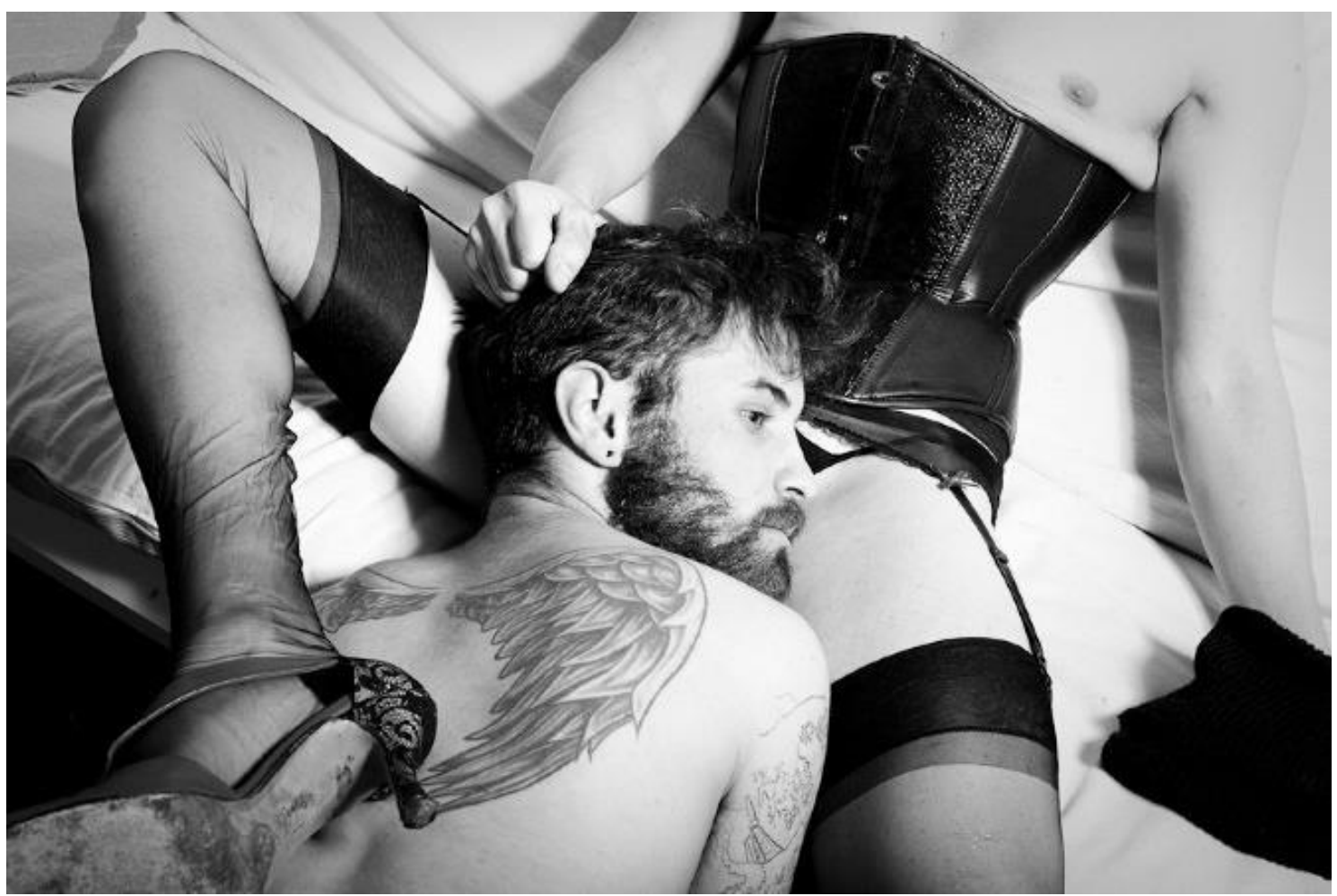

Figure 2. Confinement, Abel Azcona. Work exhibited in Museari.

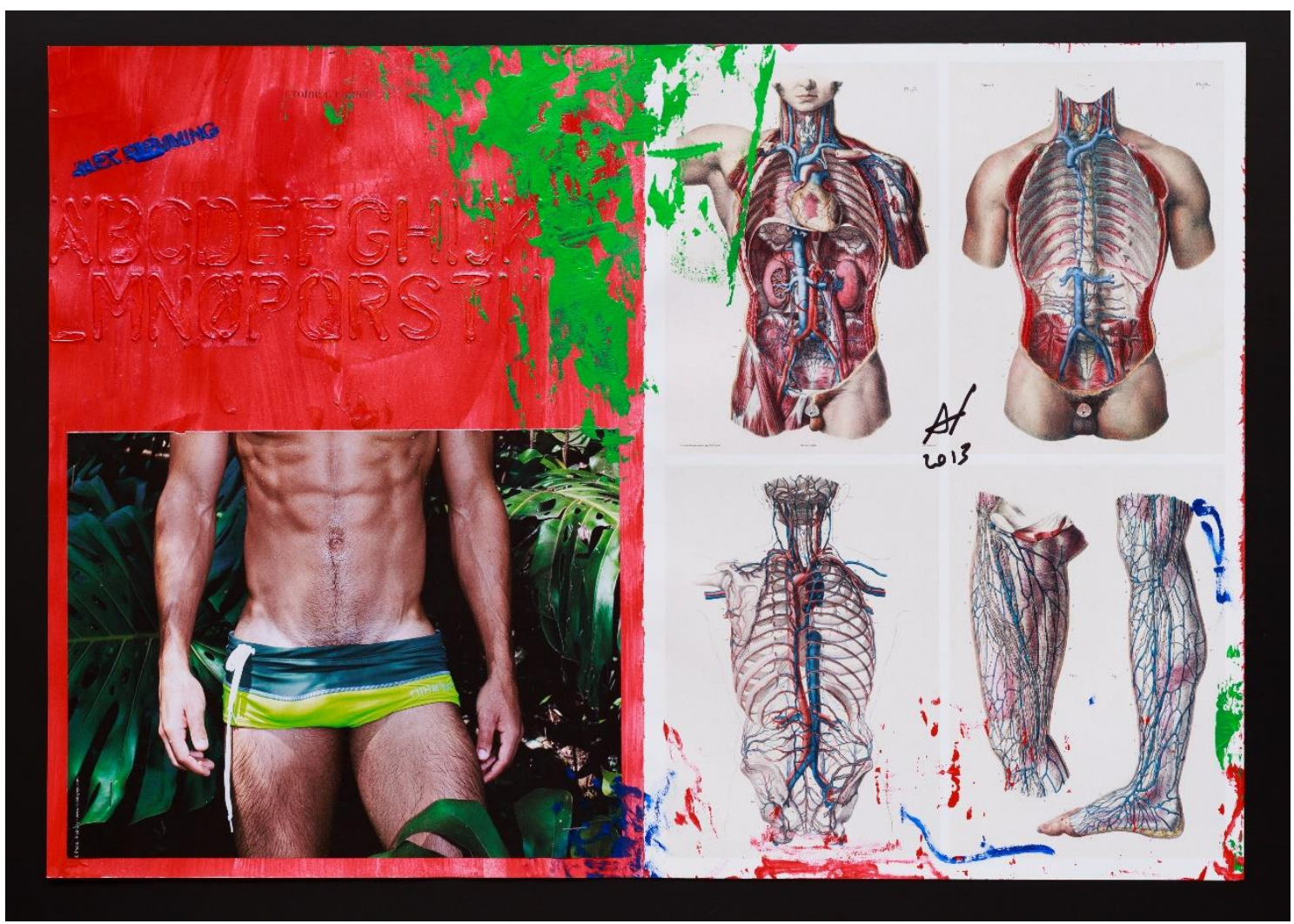

Figure 3. Collages 6, by Alex Flemming. Work exhibited in Museari. 
Alex Flemming's exhibition Body Builders (fig. 3) was chosen by $9 \%$ of the students. Flemming lives between two cities that are world capitals of art: São Paulo, the Brazilian city in which he was born, and Berlin, the European metropolis where he lives with his husband Henrique Luz. Flemming has received international recognition as a photographer, painter, sculptor, printer, multimedia artist, and poet. Always surprising and somewhat enigmatic, he constructs his personal narrative through the creative use of his own clothes, but he also reflects the social reality through portraits and approaches suggestive to the human skin.

$12 \%$ of the students chose the exhibition Identity Constructions, by Mar C. Llop, who started this project in the spring of 2013. To explain the idea of gender construction, Llop uses texts and photographs of bodies that elude the male/female dichotomy (fig. 4). In her unique way she examines the evolution of the bodies of transsexual people (Planella, 2015). Since the moment she decided to transition from the gender that she was assigned at birth, she has been meeting people who are on the same road. One day, she started documenting and translating the experiences, feelings, thoughts, concepts, and debates of transgender people into art. Her work, which occupies the space between pink and blue, between black and white, can be interpreted as looking for a body and looking for a form of expression that feels comfortable.

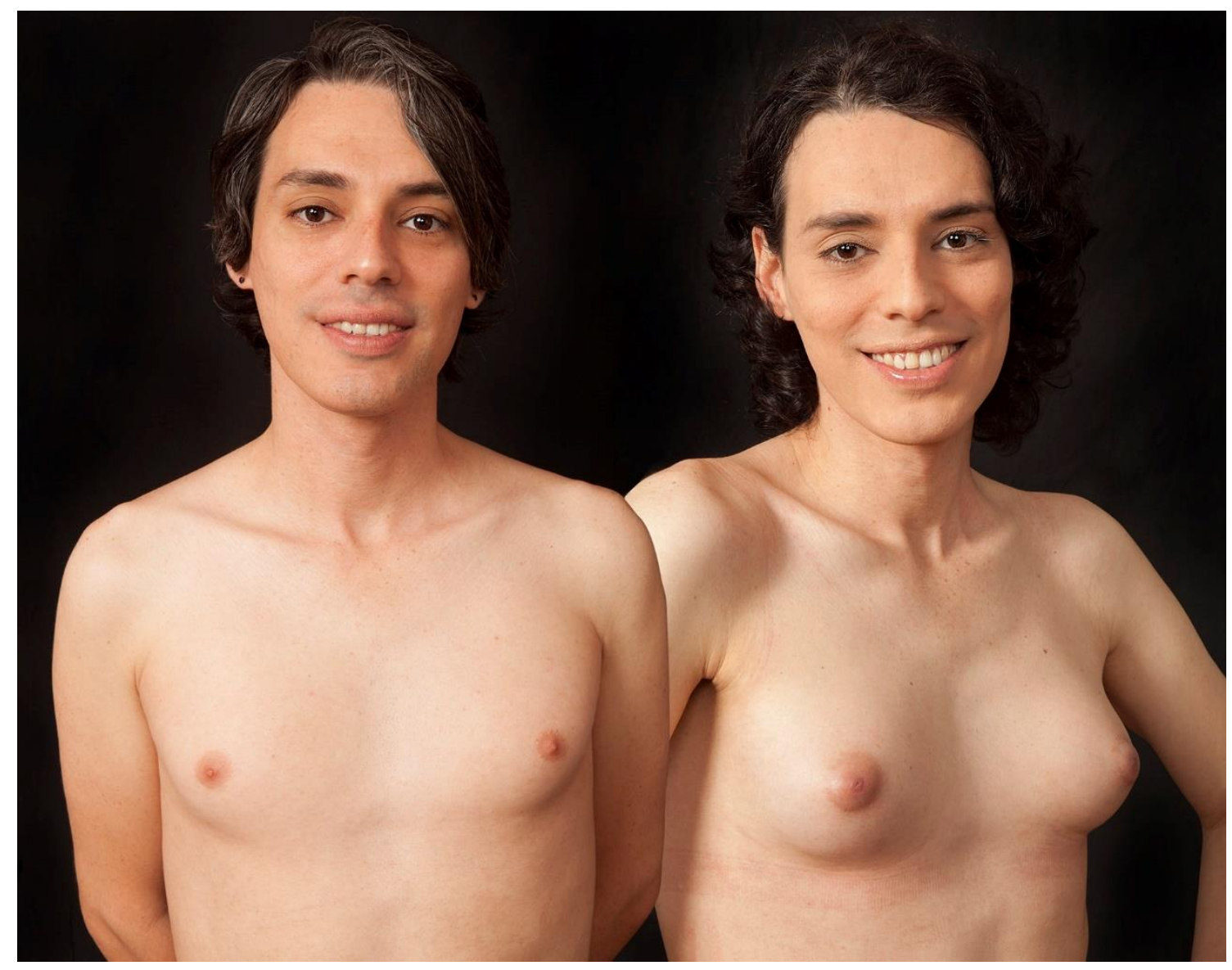

Figure 4. TR Gabrielle, by Mar C. Llop. Work exhibited in Museari. 


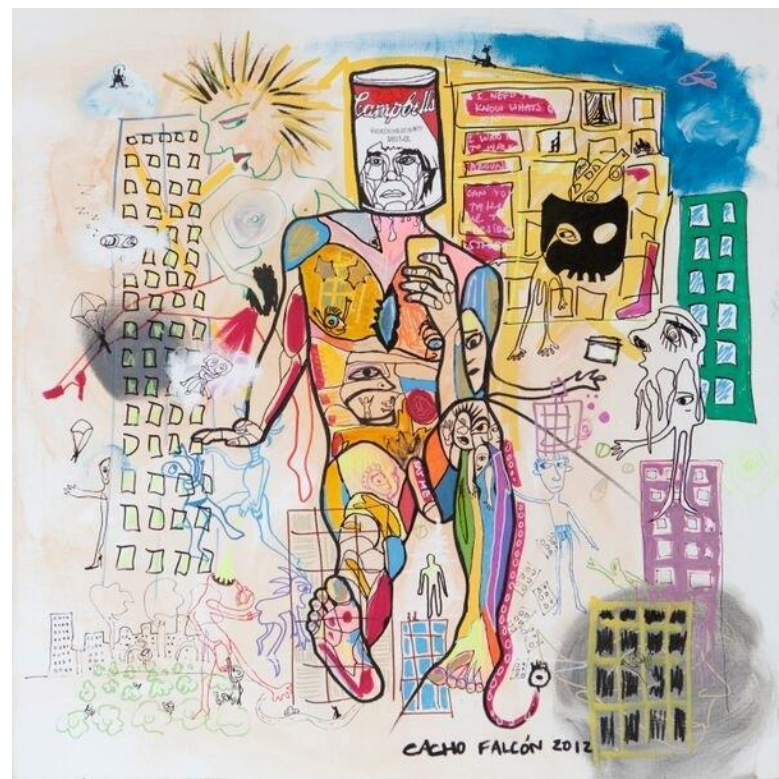

Figure 5. Bodies and Cities, by Cacho Falcón. Work exhibited in Museari.

The exhibition Bodies and Cities by the artist Cacho Falcón was chosen by $7 \%$ of the students. Falcón questions society, particularly its conceptions of beauty and success. Whoever studies his works will find that they ask countless questions and offer an infinite number of answers. Some are characterized by a naughty innocence, others offer sharp satire, but all of them attest to Falcón's mastery which is present in every detail, every stroke, every fragment that unfailingly leads the observer to seriously question the status quo.

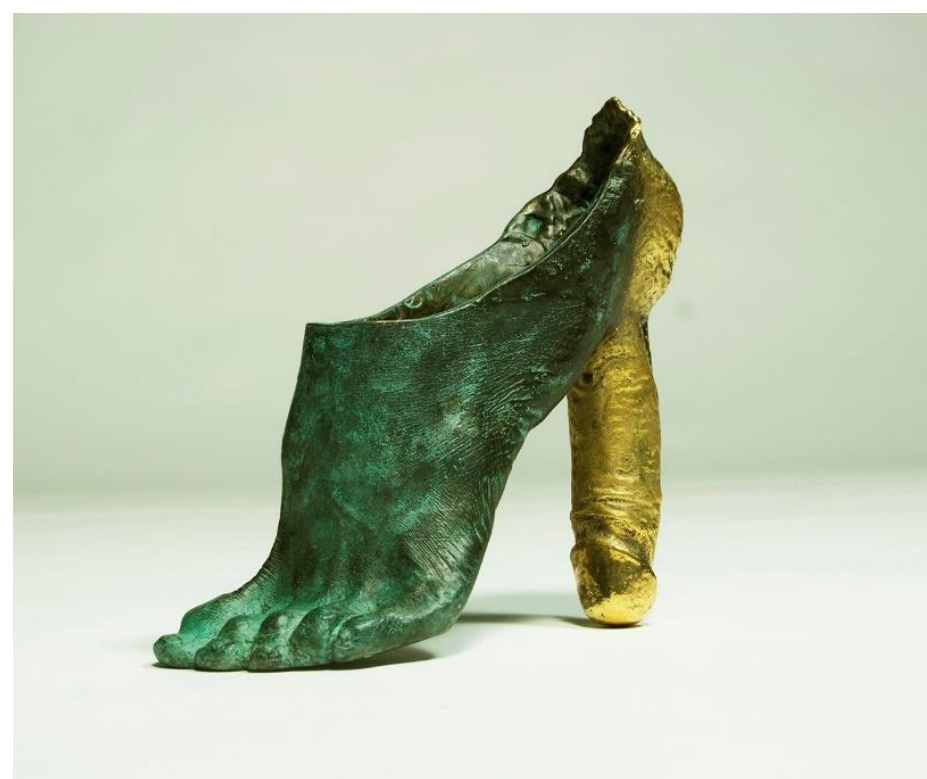

Figure 6. Sucking Heels, by David Vila. Work exhibited in Museari.

The artist David Vila's exhibition De cuerpo presente was selected by $8 \%$ of the students. Body and matter - these are the concepts with which the work of David Vila is most strongly associated (fig. 6). In this series of works based on his personal experience, a retrospective of a trip is used to reflect 
on the fundamental issues of existence, such as the relationship of the body with the environment, with itself, or with other bodies, all of which are connected with the search for identity.

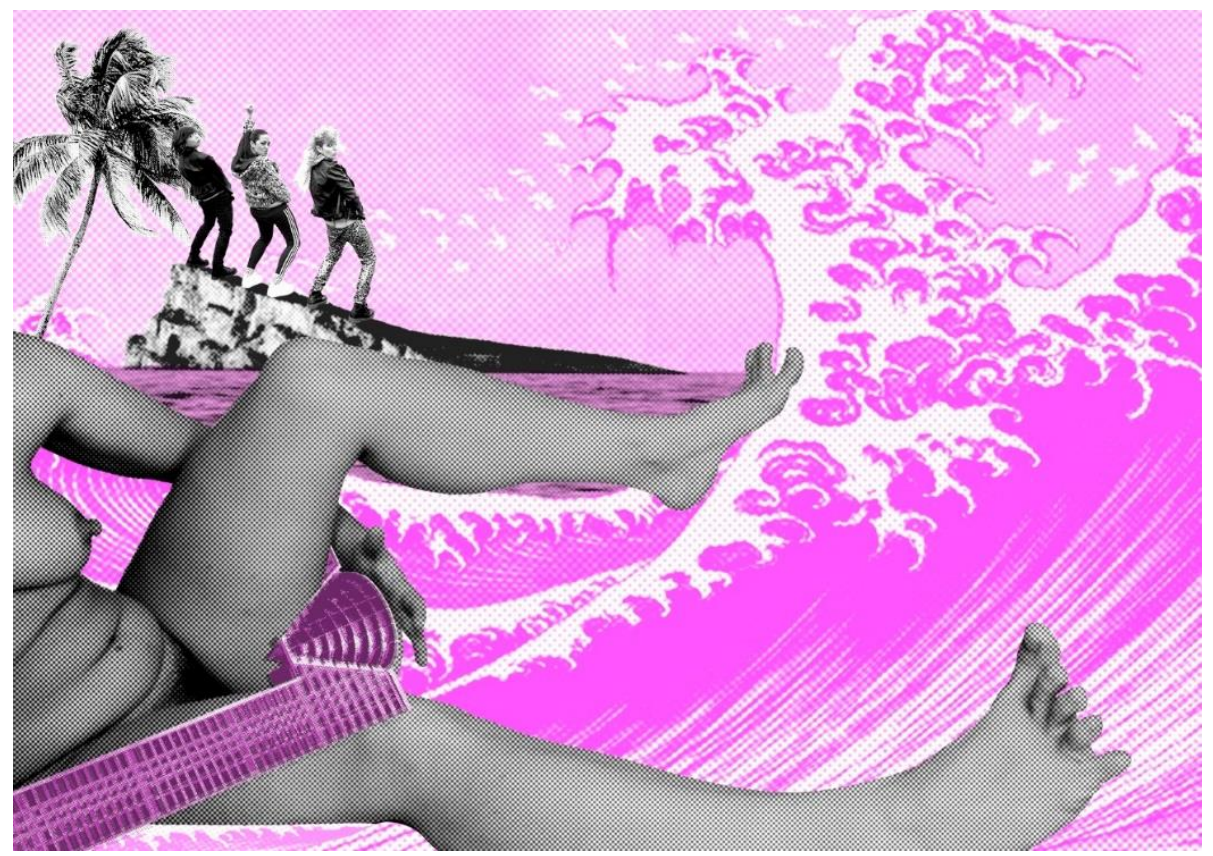

Figure 7. Follarse la ciudad Vol. III (Hokusai squeerting*), postcard, various sizes, by O.R.G.I.A group. Work exhibited in Museari.

The O.R.G.I.A exhibition Fucking the City Vol. III was chosen by $7 \%$ of the students. Fucking the city is an open project that questions the public order of the western (bourgeois and heterocentric) polis, and perverts the concept of the "souvenir" to highlight the tourist commodification that the major world capitals produce from their most polished image (fig. 7). Using the imaginary of the giantessmonster, as well as pulp and fanzine iconography, a quasi-alien and hypersexual invasion of the urban public space is carried out to resignify it, and the symbolic values of a certain type of (phallic) architecture are permuted. In this way, the city is redefined as a sexual playground for "the invader," where dichotomies such as active-passive, public-private, and male-female are reversed. Desire and drive are engines for chaos and the imbalance of the characteristic urban system.

$10 \%$ of the students chose the exhibition Think a Brazil Black and Woman by Maria Macêdo, artist, researcher, and teacher, with a degree in visual arts from the URCA Universidade Regional do Cariri. Member of the NZINGA research group: Novos Ziriguiduns (Inter) Nacionais Gerados na Arte / CNPq. She is a researcher in the YABARTE project "Processos gestacionais na arte contemporânea a partir dos pensares e fazeres negros femininos." We highlight her performance art with a vindictive view of blackness and the struggle of women (fig. 8). 


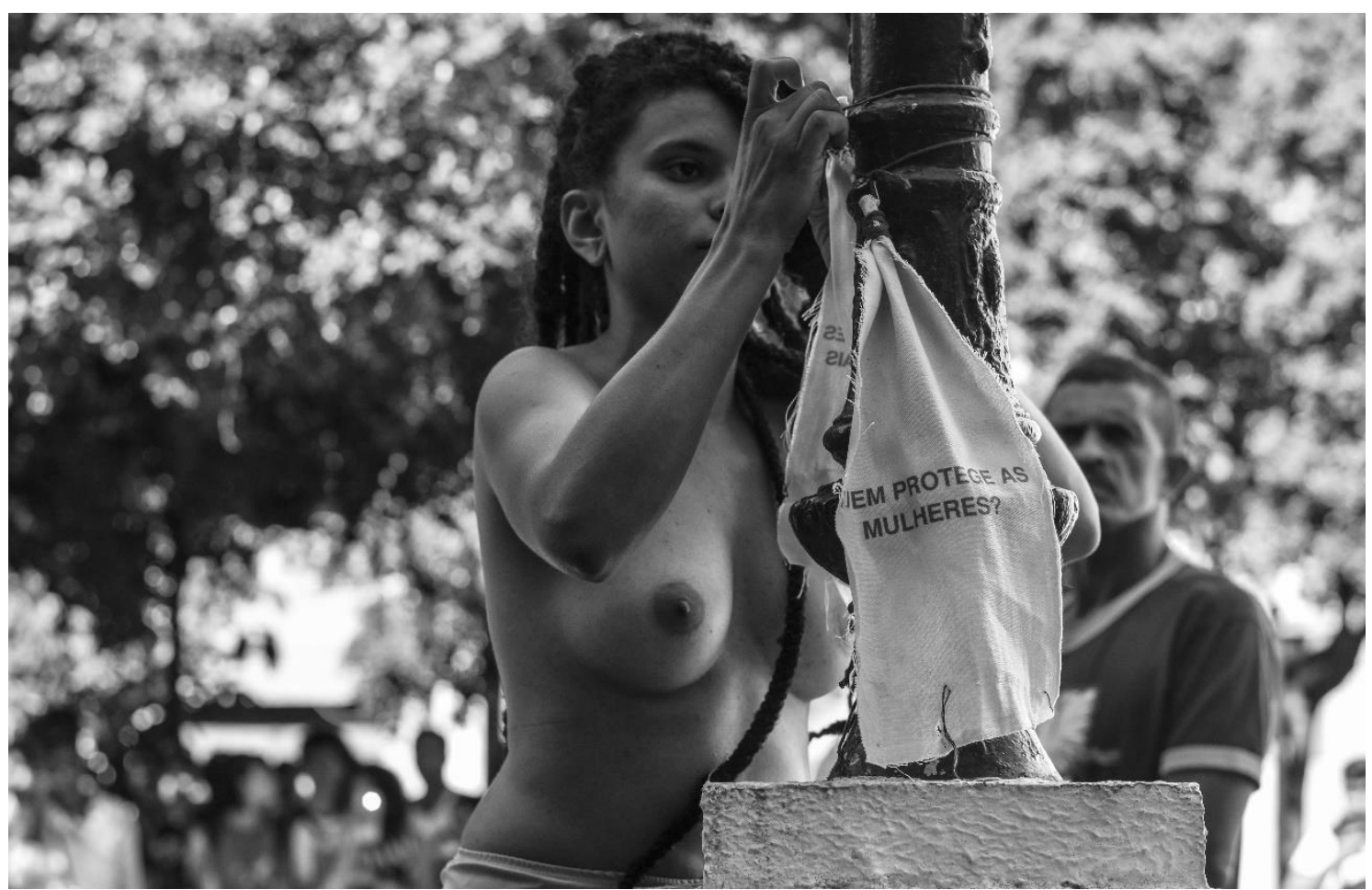

Figure 8. Performance Tálamo (2019, Crato-CE, Brasil) by Maria Macêdo. Photo: Jaque Rodrigues. Work exhibited in Museari.

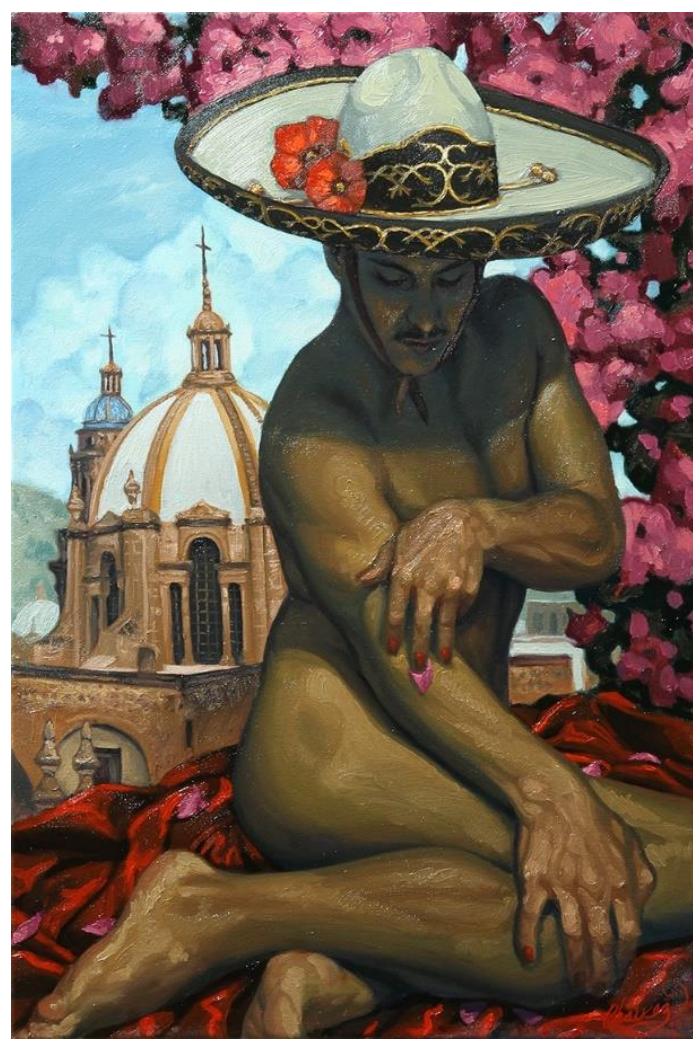

Figure 9. Carica baja, by Fabian Cháirez. Work exhibited in Museari. 
The Mexican artist Fabián Cháirez is best known as the author of the controversial painting of a naked Emiliano Zapata riding a horse, which attracted public attention and led the family of the revolutionnary Emiliano Zapata to sue the artist for "denigrating the figure of our general by painting him as gay." Born in Chiapas, Cháirez studied at the Faculty of Arts at the University of Sciences and Arts of Chiapas. In a characteristic painting style, he depicts representative Mexican figures in stereotypically queer poses that are incompatible with traditional Mexican masculinity (fig. 9). He thus seeks to draw attention to the fragility of "masculinity" and the sexual diversity present in his country. Although his works inevitably cause controversy, Fabián Cháirez takes it in his stride.

To initiate the debate, students were encouraged to present the works of art they had chosen to the whole class and comment on them. Afterwards, a workshop session took place during which the chosen models were explained in detail. This exercise was designed to familiarize students with nonnormative sexualities, and to generate inclusive activities for the class. We then carried out a diagnostic process, evaluating not only this activity but also others involving theoretical reflections and the students' prior knowledge on the subjects discussed in class. We asked the students to fill in a questionnaire about their attitudes towards sexual minorities and their knowledge about nonnormative sexualities. Based on the diagnosis, the responses were organized into two categories: 1) Knowledge about LGBT cultures and 2) Design of art activities for primary school students.

\section{Knowledge about LGBT cultures}

We found that while the students lacked knowledge about non-normative sexualities, they found them very interesting. The questionnaire also revealed that the respondents were unfamiliar with visual representations of non-normative gender and sexuality, and that they harbored prejudices towards sexual minorities. Below is a sample of responses to the question: "Did you ever considered the importance of images of LGBT cultures before enrolling in the course?"

LGBT issues are very rarely explored in school, and very few teachers would know how to make [gay and lesbian students] feel safe, understood, and included. (student 19)

The topic [non-normative sexuality] challenges us to aim for real equality in school. The matter deserves our full attention and these presentations are a good pretext to discuss the subject with our students. (student 65)

Although these works can sometimes make the viewer smile, you have to dig a little deeper and see the message they convey to us. (student 80 )

We found evidence that before taking part in the workshop the students had not considered sexual diversity as a theme in art, nor had they imagined LGBT culture in terms of a visual scenario. The vast majority (89\%) confirmed that they had discovered new motivations and found the workshop attractive. 
In this sense, our work with the students really challenged them, since it provided new knowledge and allowed them to reflect on identity, inclusion, and social justice. The students were then asked to consider on the power of art and its potential for social transformation. Thus the discussion moved towards the possibilities that inhabit the field of visuality.

\section{Design of artistic activities for primary school students}

Initially this category generated doubts among the students, who are not used to considering artistic solutions to problems. Since their prior training did not involve much attention to the visual arts, they were mostly unfamiliar with the visual potential of artistic resources:

We must adopt an inclusive language, avoid derogatory or outdated terms like "hermaphrodite," and eliminate harmful language, such as talking about "normal" boys and girls. (student 9)

The exhibition touched me very deeply because in my family there is an openly homosexual person, something that still has negative consequences, since part of our society does not accept [homosexuality]. (student 33)

Based on the stories incorporated into this diagnosis, the participants developed their own plans for artistic activities. We put the ideas of each participant at the center of the analytical and critical process (Pook, 2020). The students' work responded to such relevant and burning issues as the need to defend human rights and respect people who transgress sexual norms. We identified stereotypes that are part of the students' daily lives and asked them to problematize the stereotypes based on their own experiences, attitudes, and ways of showing themselves to the world. Once the selected works of art were presented, we initiated a debate to determine which aspects were the most interesting or motivating and how students could apply what they learned in the primary school classroom where they will work in the future (Bourriaud, 2009).

The process described above allowed us to critically evaluate the students' proposals, which conveyed feelings and raised problems. It also served to explain the use of different materials and procedures, applying elements of visual language for expressive purposes (Errázuriz Larraín and Fermandois-Schmutzer, 2021).

Next, we assessed the students' knowledge of representations related to the struggle against homophobic and transphobic bullying. They were encouraged to construct meanings evidencing symbolic violence in their daily environments, looking especially for meanings in visual representations (Mirzoeff, 2006). This led to a debate on the role of LGBT claims and possibilities of intervening through art, as well as the communicative capacity that visual representations entail. This element of the workshop gave the participants a better understanding of the LGBT experience. Some ideas that emerged in the course of the assessment addressed these issues: 
It seems to me that we need to make the population aware of the real problems that women and LGBT groups face. (student 41)

I liked seeing the exhibitions and they made me think and react. (student 77)

The answers to questions about gender and sexual diversity were less precise than in the case of previous questions, but they also incorporated elements of reflection: I think that it is a really important issue, that must be dealt with, and that it has a lot to do with the education received. (student 3)

Transgender people are among us and the spaces they occupy and should occupy are the same as those of any other person, but their presence does not go unnoticed due to the transphobia that exists. They are stared at, they are pointed out, observed, scrutinized in a way that has nothing to do with the way other people are looked at. It is the gaze that stigmatizes. (student 18)

We live in a totally binary society in which the duality of roles that men and women must adopt is still emphasized. (student 36)

The pride flag represents much more than belonging to a group. It is the reflection of a group that has been fighting for its rights for years. It is one of the strongest symbols that makes the group visible. It sends a direct and clear message in defense of diversity, with six simple stripes and one word. It is simple but all that it entails is complex. (student 54 )

We questioned the collective imaginary about gender to develop a deconstructive exercise on the social meanings of the images present in the school discourse on gender (Foucault, 1990). At the methodological level, we attempted to link the topic of the discussion with personal experience, verifying the students' accounts of activities and representations that are "for boys or for girls," questioning the traditional gender divisions and roles. The reflections of the students point to the questioning of social duty, freedom of expression, and the need to build educational scenarios freer of stereotypes.

While $83 \%$ of participants said they were interested in and concerned about LGBT issues, only 6 said they had participated in LGBT initiatives, protests, or solidarity activities. Most of the participants had not regularly participated in art-related activities like those they had developed and presented, yet they declared the intention to do so in the future. Thus, the majority of the participants - future primary school teachers - had developed a social concern. 
When asked "How important is it to raise LGBT issues in education?" $48 \%$ of the respondents said they considered it to be very important, $43 \%$ important, and only a minority of $9 \%$ as saw it as being of average importance. Our findings were similar in relation to the question "How important do you think art is in incorporating LGBT issues in the classroom?" $53 \%$ considered art important, $42 \%$ very important and only $5 \%$ saw it as being of average importance. In the case of the question "Do you think it is important to address LGBT issues in a transversal way in primary education?" all the answers were positive. The participants also considered it necessary to introduce visual literacy in the first years of school. All this points to a greater concern for the presence of art education in the classroom (Irwin and O'Donogue, 2012).

The answers to such questions as "Do you think that in the case of non-normative sexuality, being a man or a woman can make a substantial difference?" or "Do you think that discussing the LGBT experience can improve primary-school education?" provided us with significant data on what this generation of students thinks. The majority recognizes gender inequalities due to the heteropatriarchal social structure that still persists and makes it difficult to empower women as a group (Butler, 2010). A minority (23\%) is unaware of gender inequalities and does not detect the existence of social micromachisms (everyday instances of male chauvinism). All the participants affirmed the LGBTIQ minority and their answers indicated that they understood this group to be susceptible to difficulties in the social sphere. They considered it appropriate to introduce all these topics in the classroom via art and visual culture. They had clearly understood that the normative gaze, which stigmatizes and systematically eliminates otherness, can be harmful to many people who are affected by discrimination, violence, or invisibility.

The surveys also showed us that there is great interest in issues such as violence against trans people or bullying children who do not conform to the sex and gender norms. Despite their social and political awareness, we found that the students were not aware of the extent to which both the media and the school curriculum itself marginalize these issues. After analyzing the obtained results, we found that future teachers need more training on issues of non-normative gender and sexuality, to raise awareness of the educational power of a school curriculum free of taboos.

\section{Conclusions}

This research project revealed important information about the treatment of LGBT diversity in the training of primary school teachers. We examined this issue from the perspective of art education and we came to the conclusion that non-normative gender and sexuality continue to be practically non-existent in both school curricula and teacher training. The absence of this subject matter in education erases a problem affecting millions of people, including teachers and students. Fears and prejudices, particularly homophobia, lead individuals to conceal their non-normative gender or sexuality, which impedes pedagogical work that is invested in promoting respect and inclusion of difference. 
The educational approach we propose, which foregrounds the defense of human rights and respect for diversity through the study of art, incorporates visuality into the teaching resources and involves the analysis of objects made by artists involved in dissents movements, as well as their modes of creation, presentation, consumption, and critical reception (Even-Zohar, 1990). In this approach, which is grounded in cultural studies, works of art are not treated as autonomous objects but rather as tools that allow us to understand the organization of contemporary societies and the power relations that structure them. These visual artifacts are not to be treated as simple cultural symbolic representations of the policies at work in LGBT communities. We wish to underline their capacity to produce and strengthen collective identities, and to renegotiate their meaning.

Identity should not be understood as something fixed and essential, as a naturally stable and unaltered unit, but as a strategic and situated concept. Identity is also an aesthetic issue, a fact that calls for a broad reflection on the cultural and political dimensions of non-normative gender and sexuality. Dissident artistic practices, which must also be considered as militant strategies, attest to the unique place of the individual in active dissent, which always has an aesthetic aspect. Knowledge about such dissident practices helps us to better understand the problems and modalities of subjective and affective dynamics in the articulation of iconographic and theoretical corpus, as well as in the construction of representations.

We need to improve the teaching of art at the primary school level since students who are encouraged at an early age to closely examine images of the LGBT world will be able to perceive the creative possibilities of dissidents. At the same time, we see a need to update the language in which LGBT issues are discussed in school, as well as the visual art resources used by teachers who now heavily rely on digital technology. The use of an online museum like Museari fosters the new approach we propose. Our goal is to bring the LGBT universe closer to university students, showing it from multiple perspectives and attending to aesthetic, cultural, ethical, and social involvement issues. The workshop sessions we conducted at the University of Valencia as part of our research project have shown that by working with LGBT dissident art it is possible to overcome the prejudices students may harbor towards the LGBT minority, and thus to release the creative potentials of all students.

\section{Works Cited}

Alonso-Sanz, Amparo, Paula Jardón and Yolanda Lifante (2019), "The Role of the Classroom's Images: Study of Visual Culture at Three Schools", Visual Studies, 34.2: 107-118. https://doi.org/10.1080/1472586X.2019.1653223

Appiah, Kwame Anthony (2018), The Lies That Bind Rethinking Identity: Creed, Country, Color, Class, Culture, New York, NY, Liveright Publishing Corporation.

Arriaga, Amaia and Imanol Aguirre (2013), "Concepts of art and interpretation in interviews with educators from Tate Britain". International Journal of Art and Design Education, 32.1: 126-138. https://doi.org/10.1111/j.1476-8070.2013.01740.x 
Barthes, Roland (1986), Lo obvio y lo obtuso. Imágenes, gestos, voces, Barcelona, Paidos.

Benjamin, Walter (1969), The Work of Art in the Age of Mechanical Reproduction. New York, NY, Schocken Books.

Bourriaud, Nicolas (2009), The Radicant. New York, NY, Lukas \& Sternberg.

Briggs, Asa and Peter Burke (2009), A Social History of the Media. From Gutenberg to the Internet, Cambridge, UK, Polity Press.

Butler, Judith (2010), Gender Trouble: Feminism and the Subversion of Identity, New York, NY, Routledge.

Chung, Sheng Kuan (2007), "Media Literacy Art Education: Deconstructing Lesbian and Gay Stereotypes in the Media", International Journal of Art and Design Education, 26.1: 98-107. https://doi.org/10.1111/j.1476-8070.2007.00514.x

Duncum, Paul (2008), "Holding Aesthetics and Ideology in Tension", Studies in Art Education, 49.2, 122-135.

(2015), "Transforming Art Education into Visual Culture Education through Rhizomatic Structures", Anadolu Journal of Educational Sciences International, 5.3: 47-64. https://doi.org/10.18039/ajesi.66849

Eisner, Elliot W. (2002), The Arts and the Creation of Mind, New Haven, Yale University Press.

Errázuriz Larraín, Luis and Joaquín Fermandois-Schmutzer (2021), "Formación docente para la educación artística en Chile. El desafío cultural pendiente en las escuelas primarias", Arte, Individuo y Sociedad, 33.1: 49-69. https://doi.org/10.5209/aris.67126

Escaño, Carlos (2019), "Biopolitical commons in the postdigital era", Postdigital Science and Education, 1.2: 298-302. https://doi.org/10.1007/s42438-019-00041-2

Escudero Ledesma, Irene (2017), "La educación como espacio de resistencia. Una propuesta desde las Artes y la Educación Social asentada en la pedagogía queer (pedagoqueer)", InterAlia, 12: 40-52.

Even-Zohar, Itamar (1990), "Polisystem Theory", Poetics Today, 11.1: 9-26.

Foucault, Michel (1977), Discipline and Punish: The Birth of the Prison, New York, Pantheon Books. (1990), The History of Sexuality, Vol. 1: An Introduction, New York, Vintage Books.

Freire, Paulo (2015), Pedagogia da autonomia: saberes necessários à prática educativa, Rio de Janeiro, Paz e Terra.

Giroux, Henry (2018), Pedagogy and the politics of hope: Theory, culture, and schooling: A critical reader, New York, NY, Routledge.

Greteman, Adam J. (2017), "Helping Kids Turn Out Queer: Queer Theory in Art Education", Studies in Art Education: A Journal of Issues and Research, 58.3: 195-205.

Hamlin, Jessica and Joe Fusaro (2018), "Contemporary Strategies for Creative and Critical Teaching in the 21st Century", Art Education, 71.2: 8-15.

Hernández, Fernando and Juana M. Sancho-Gil (2015), "A learning process within an education research group: an approach to learning qualitative research methods", International Journal of Social Research Methodology, 18.6:651-667. https://doi.org/10.1080/13645579.2015.1049468

Huerta, Ricard (2010), Maestros y museos. Educar desde la invisibilidad, Valencia, PUV. 
_ (2016), "The cemetery as a site for aesthetic enquiry in Art Education", International Journal of Education through Art, 12.1: 7-20. https://doi.org/10.1386/eta.12.1.7_1

Huerta, Ricard and Ricardo Domínguez (2020), "Por una muerte digna para la educación artística", EARI Educación Artística: Revista de Investigación, 11: 9-24.

https://doi.org/10.7203/eari.11.19114

Irwin, Rita and Dónal O'Donoghue (2012), "Encountering pedagogy through relational art practices", International Journal of Art \& Design Education, 31.3: 221-236.

Karpati, Andrea, Kerry Freedman, Juan Carlos Castro, Mira Kallio-Tavin and Emiel Heijnen (2017), "Collaboration in Visual Culture Learning Communities: Towards a Synergy of Individual and Collective Creative Practice", International Journal of Art and Design Education, 36.2: 164-175. https://doi.org/10.1111/jade.12099

Mérida Jiménez, Rafael M. (2020), "Founding and Ineffable Identities: Pelagius, Virgin and Martyr", Imago temporis. Medium Aevum, 14: 165-184.

Mirzoeff, Nicolas (2006), "On Visuality", Journal of Visual Culture, 5.1: 53-79.

Panciroli, Chiara (2016), "Los bienes culturales como patrimonio educativo", EARI Educación Artística Revista de Investigación, 7: 86-99. https://doi.org/10.7203/eari.7.8158

Péchin, Juan (2017), "Entre lo queer y lo cuir: arte, política y críticas pedagógicas en Argentina", InterAlia, 12: 86-105.

Pérez Navarro, Pablo (2018), "'Where Is My Tribe?' Queer Activism in the Occupy Movements", InterAlia, 13: 90-101.

Planella, Jordi (2015), "De cuerpos, carnes y pedagogías. Travesías corporales en la educación actual", Educación Artística y Diversidad Sexual, Ricard Huerta and Amparo Alonso-Sanz (eds.), Valencia, Universitat de València, 43-59.

Planella, Jordi and Asun Pie (2012), "Pedagoqueer: resistencias y subversiones educativas", Educación XX1, 15.1: 265-83.

Pook, Zooey Sophia (2020), "The Challenge of Implementing Preferred Gender Pronouns: Queer Autonomy in the Age of Information Technologies", InterAlia, 15: 6-16. https://doi.org/10.51897/interalia/BTAW6071

Rodríguez Ortega, Nuria (2018), "Five Central Concepts to Think of Digital Humanities as a New Digital Humanism Project", Artnodes: revista de arte, ciencia y tecnología, 22: 1-6. https://doi.org/10.7238/a.v0i22.3263

Rolling, James H. (2017), "Arts-Based Research in Education". Handbook of Arts-Based Research, P. Leavy (ed.), New York, Guilford, 493-510.

Sennett, Richard (2009), The Craftsman, London, Penguin Books.

Stake, Robert E. (1995), The Art of a Case Study Research, London, Sage Publications.

Vanegas Zubiría, Carlos (2020), "Aproximaciones a la historia del arte y el museo: Belting, Danto y Hegel", H-ART. Revista de historia, teoría y crítica de arte, 8: 305-324.

https://doi.org/10.25025/hart08.2021.14

Yin, Robert K. (2009), Case Study Research, London, Sage. 